\title{
Value of the Uterine Artery Color Doppler Study in Detection of Placenta Accreta
}

\author{
MONA AL SAYED ELKAFRAWY, M.D.; HANAN ABDELMONAEM, M.D. and \\ HALA MAGHRABY SHERIEF, M.D.
}

The Departments of Obstetrics \& Gynecology and Radiology, Faculty of Medicine, Al-Azhar University

\begin{abstract}
Background: Placenta accreta is serious pregnancy complication associated with various maternal morbidity and mortality and is currently the major cause of postpartum hysterectomy.

Aim of Study: Evaluation of the value of the uterine artery color Doppler ultrasonography in the detection of placenta accrete in pregnant women with previous cesarean section.

Patients and Methods: This study was a prospective observational (Cohort) study was done at Al-Zahraa University Hospital (in Obstetric and Gynecology Department) in the period from December 2017 to February 2019. All women were pregnant in a singleton fetus, their gestational age ranged from 28 to 36 weeks, with history of previous cesarean section and all patients presented with anterior low inserted placenta or placenta centralis. The study included sixty pregnant women without risk factors. Patients were recruited from the causality and the antenatal care clinic with suspected placenta previa (anterior low inserted or complete centralis) during the Third trimester of pregnancy which was confirmed by abdominal ultrasound. All the women in this study were subjected to Complete history taking, physical examination, and routine obstetric ultrasound study for detection of the location of the placenta after the 28 th week of gestation and Color Doppler ultrasound study of the uterine artery. The intraoperative findings of each case were compared with the preoperative imaging findings.
\end{abstract}

Results: Placenta accreta was found in $41.7 \%$ of the studied women. The study reported that the mean RI determined by color Doppler ultrasonography of the uterine artery was significantly low in placenta previa with accreta. As it was $0.656 \pm 0.190$ for placenta without accreta and $0.557 \pm 0.127$ for placenta accreta $(p<0.001)$. The cutoff value of mean uterine artery Doppler PI for placenta accrete obtained from ROCK curve was $\leq 0.93$, AUROC (0.636), SN (64\%), SP $(74.3 \%)$, PPV (64\%), NPV (71.3\%), accuracy (70\%) and CI (95\%).

Conclusion: This study concluded that ultrasound and uterine artery Doppler had a role in detection of placenta accreta in cases with previous CS. The mean uterine artery RI was significantly lower in the placenta accreta compared to placenta previa without accreta.

Correspondence to: Dr. Mona Al Sayed Elkafrawy E-Mail: drsaad53@yahoo.com
Key Words: Color Doppler - Uterine artery - Placenta accrete - Placenta previa accrete - Placenta previa.

\section{Introduction}

ABNORMALLY Invasive Placenta (AIP) including a spectrum of conditions where the chorionic villi are abnormally adherent to the myometrium, associated with partial or even complete absence of the decidua basalis and the stratum spongiosum. According to grades of pathologic adherence of the placenta through the myometrium and the extent of invasion of the uterine muscular wall, it can be classified into placenta accreta, increta and percreta [1]. One of the serious and may be fatal complication of the placenta accreta is massive intrapartum and postpartum hemorrhage [2] .

The strict etiology is indefinite, but it has been postulated to be correlated to a failure of normal decidualization in the area of the utrine scar causing defect of the endometrial-myometrial interface allowing abnormal deep placental anchoring villi and trophoblast infiltration [3]. The role of the decidua as barrier is missing in this condition and the invasive trophoblasts may attack the myometrium to the lowest point at variable levels, from the most shallow (placenta accreta) to deeper myometrial invasion (placenta increta), with breach of the uterine serosa and may be attack the nearby organs [4].

Placenta Accreta is considered when the placenta attaches deeply into the uterine wall without penetration of the uterine muscle. Placenta Increta is considered where the placenta attaches more firmly and deeply into the uterine wall with penetration the uterine muscle. Placenta increta represents for the patient less than $15 \%$ of all cases. Placenta Percreta is a considered when the placenta penetrate the entire uterine wall and attaches to 
the nearby organ mainly the bladder. Incidence of placenta perecreta is less common than the other three conditions (RCOG, 2011) [5].

The most common risk factors for placenta accreta common are previous cesarean section with placenta previa, prior uterine surgery or curettage, maternal age over 35 multiparity and Asherman syndrome, all of which may be the cause of injury to / or lack of the decidua basalis [6]

Most of patient with placenta accreta are asymptomatic. Symptoms in these cases may include vaginal bleeding and cramp. These symptoms are mainly seen in patients having placenta previa. In rare severe cases, uterine rupture secondry to placenta percreta may occur causing hypovolemic shock, the patient is complaining of abdominal pain and hypotension. These serious conditions can occur at any time throughout pergnacy from early first trimester to full term [7].

Severe internal hemorrhage that can lead to maternal and/or fetal death may be associated with placenta accreta. The possibility of uterine rupture may be associated with Placenta percreta in some cases it may penetrate the uterine wall and attack the bladder causing hematuria [8]. Over the past four decades the increasing rate of placenta accreta is most likely due to the increased rate of cesarean delivery [9]

Placenta accreta is suspected to be pesent in women who have a history of cesarean or prior uterine operation and those who have placenta praevia, particularly anterior. Careful prenatal diagnosis significantly affecting the outcome of this circumstance. It gives the chance to make a delivery chart that correctly anticipates the predictable blood loss and other suspected complications of delivery. In addition, it helps to avoid complications perfectly and needs a multidisciplinary surgical team to be present at the time of delivery [10].

Ultrasonography is the first choice diagnostic modality for antenatal diagnosis of placental abnormality. Ultrasound diagnostic features of accreta may be detected early in the first trimester; however, most women are diagnosed in the second and third trimesters [11]. Second and third trimester gray-scale $2 \mathrm{D}$ sonographic findings including loss of continuity of the uterine wall, multiple vascular lacunae (irregular vascular spaces) inside placenta, giving "Swiss cheese" look nearby to the placental implantation site, lack of a hypoechoic margin (myometrial zone) between the placenta and the myometrium, bulging of the placental and myome- trial location into the bladder [12]. However, the diagnosis of placenta accreta in the first trimester is rare. Its features include: The low implantation of the gestional sac in the lower uterine segment and may be associated with multiple irregular vascular spaces within the placental bed [13]

Transvaginal ultrasound is more precise than trans-abdominal ultrasound in detection of the placental location and detection of the presence of placenta praevia [14]. Color Doppler study may facilitate the diagnosis. The most common features suggesting the diagnosis of accreta is Turbulent lacunar blood flow. Other Doppler findings of placenta accreta spectrum include increased subplacental vascularity, gaps in myometrial blood flow, and vessels bridging the placenta to the uterine margin [6].

\section{Patients and Methods}

The study was done at Obstetrics and Gynecology Department of Al-Zhraa University Hospital, Cairo, sixty pregnant women seeking for antenatal care were included during the period from December 2017 to February 2019. All women were pregnant in a singleton fetus. Their gestational age ranged from 28 to 36 weeks, with previous cesarean section and all were presented with anterior low inserted placenta or placenta centrals.

Patients with active vaginal bleeding and with posterior inserted placenta were excluded. All cases of the study wubjected to: History physical examination(general and local), routine laboratory investigations and routine gray scale obstetric ultrasound examination for localization of the placentain the second trimester mainly after the 28 th week of gestation. Special attention on placental site and grade and placental attachment. Color Doppler ultrasound is applied on the placental bed.

Gray-scale B-mode trans-abdominal sonography and color Doppler were performed firstly used to screen the placenta. The equipment Philips (Affiniti $70 \mathrm{G}$ ). The probe used is the convex probe $(3.5 \mathrm{MHz})$ in transabdominal scanning and transvaginal probe $(6.5 \mathrm{MHz})$ for transvaginal scanning. The study is done with careful observation of the homogensity of the echogenic pattern of the placenta with proper localization of it. Special attention to its attachment, its site and its grade. Color Doppler application on the placental bed.

$2 D$ Ultrasonographic features used for diagnosis of placenta accreta:

1- Loss of Retro -placental sonolucent zone: The retroplacental zone appears as a clear zone 
between the placenta and myometrium (Fig. 1). This zone can be detected by the 12 weeks of gestation and few dilated vessels of the decidua basalis may be seen within this zone [15].

2- Vascular lacunae: Placenta accreta has a "motheaten" or "Swiss cheese" pattern with unstable flows within. It appear as an irregular spaces with smooth borders and more linear rather than rounded. Unlike the typical sinuses, They do not have the extremely echogenic boundaries (Fig. 2). This sonographic sinding has been associated with the maximum positive prognostic value for placenta accreta especially when detected in second and third trimesters [16].

3- Myometrial thinning: Progressive thinning out of the retro-placental myometrium is indicative that the placental tissue is penetrate deeply into the uterine serosa or adjacent organs, mainly the bladder. Segmental myometrial thinning of $1 \mathrm{~mm}$ is highly suspicious of placenta accreta [17].

4- Interruption of the bladder border: Loss of myometrial tissue resulting in thinning or disturbance of the vesicouterine interspace. This appears as asymmetrical interruptions of the bladder wall-uterine interspace or as the bladder wall is bulging into the uterine wall (Fig. 3). This sign is characteristic for an accurate diagnosis of placenta accreta but with poor sensitivity [18]

Color Doppler ultrasound examinations of the most suspicious area had been performed in the same time with the same doctor to look for the possibility of being placenta previa accreta.

Partial filling of the urinary bladder with small amount of fluid was used to aid the detection of the uterine wall and bladder wall serosa.

\section{Doppler ultrasound of the uterine artery:}

The cervico-corporeal junction is the main point for detection of the main branches uterine artery, with the help of color Doppler velocimetry measurements performed near to this location, either trans-abdominally or trans-vaginally.

The Color Doppler is applied to the sono-lucent placental vascular lakes seen within the placenta to detect the highest peak velocity of pulsatile venous flow within using angle correction, and the resistance index of the neovascularized arterial blood flow within the vesico-uterine interspace was recorded in the definitely abnormal patients.
The color Doppler findings suggestive for placenta accreta include:

1-A diffuse or focal lacunar flow pattern: Multiple diffusely dilated vascular channels are seen spread all over the placenta. The flow within these spaces has high- velocity turbulant pulsatile venous-type flow (Fig. 4).

2- Lack of sub placental vascular signals in the areas loosing the marginal sub placental hypoechoic zone.

3- Peripherally located sub-placental zone with markedly dilated vessels seen over.

4- Abnormal blood vessels are seen passing through the placenta and connecting it to the bladder with high diastolic arterial blood flow and interphase hypervascularity withith [19].

The patients who had all ultrasound diagnostic criteria suggestive placenta accreta were informed and counseled about and the high possibility of hysterectomy.

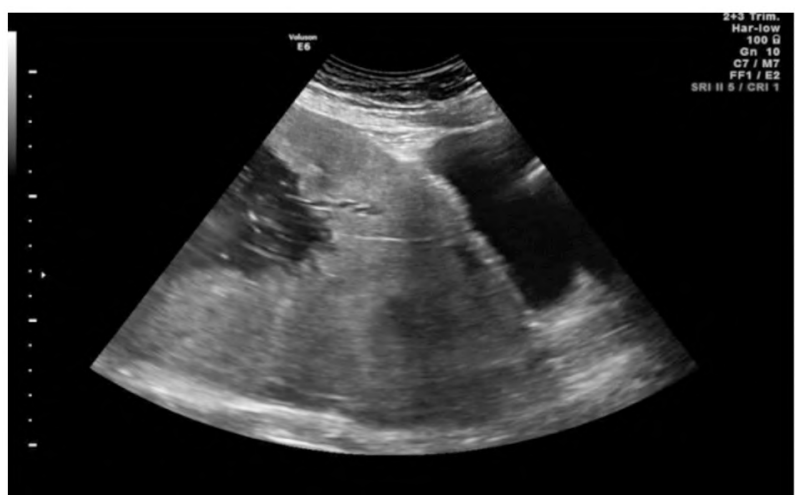

Fig. (1): 2D transabdominal US in 32 weeks gestation revealed loss of normal hypoechoic retroplacental space.

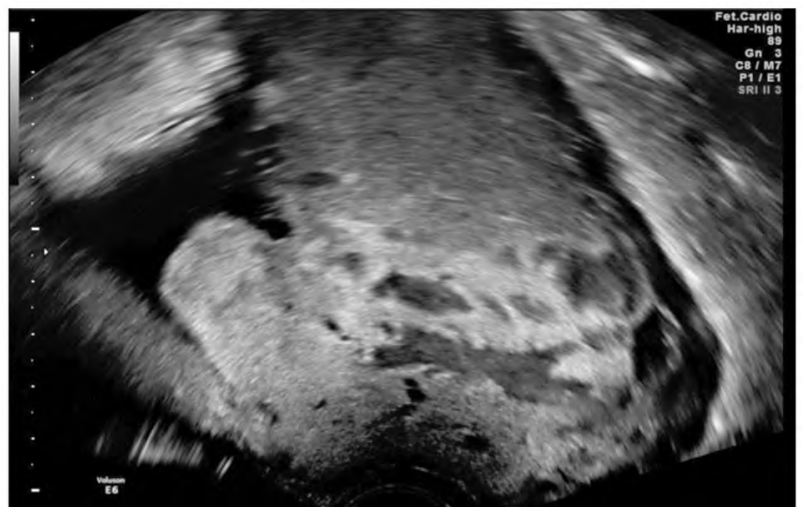

Fig. (2): 2D Transvaginal ultrasound in 33 weeks gestation with previous 4CS revealed loss of normal retroplacental space with multiple vascular lacunae within the placenta. 


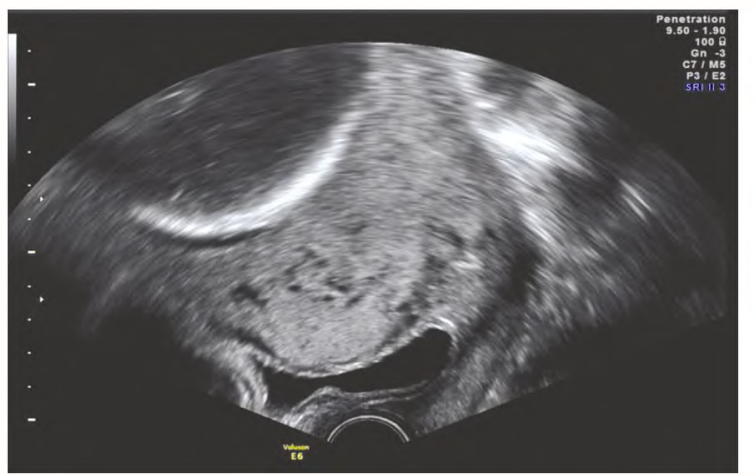

Fig. (3): 2D Transvaginal Ultrasound in 30 weels gestation with previous $3 \mathrm{CS}$ revealed disturbance of the bladdermyometrium interface suggesting placenta percreta.

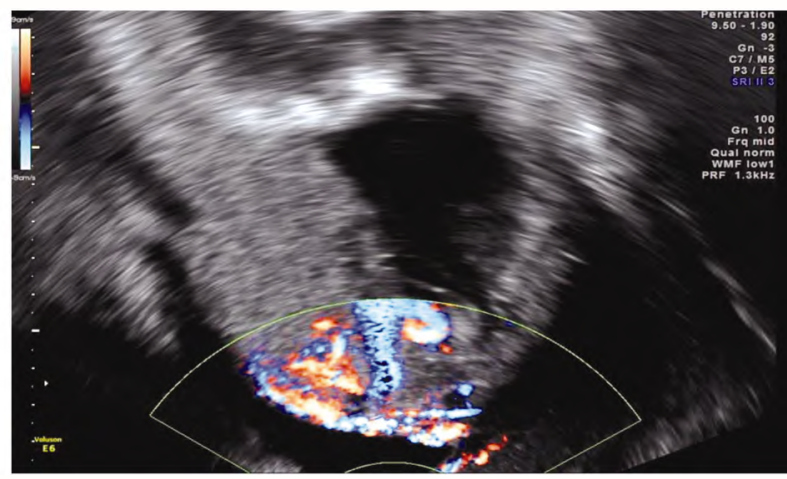

Fig. (4): 2D Transvaginal ultrasound in 34 weeks gestation with previous 4CS with application of color Doppler shows multiple placental vascular lacunae.

\section{ABNORMAL UTERINE A. DOPPLER}

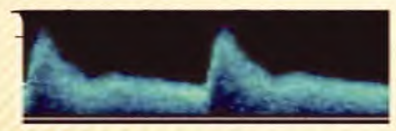

Normal impedance to flow in the uterine arteries (with the

characteristic waveform of early diastolic notching)

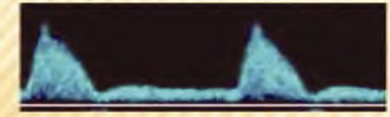

Increased impedance to flow in the uterine arteries (with the

characteristic waveform of early

diastolic notching)

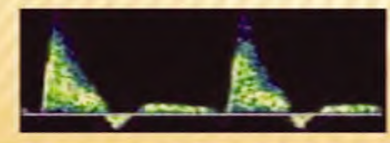

Very high resistance to flow in the

uterine arteries (with reverse

diastolic flow)

Fig. (5): Abnormal uterine artery Doppler, Qauted from Baarti, Gahtori, 2014.

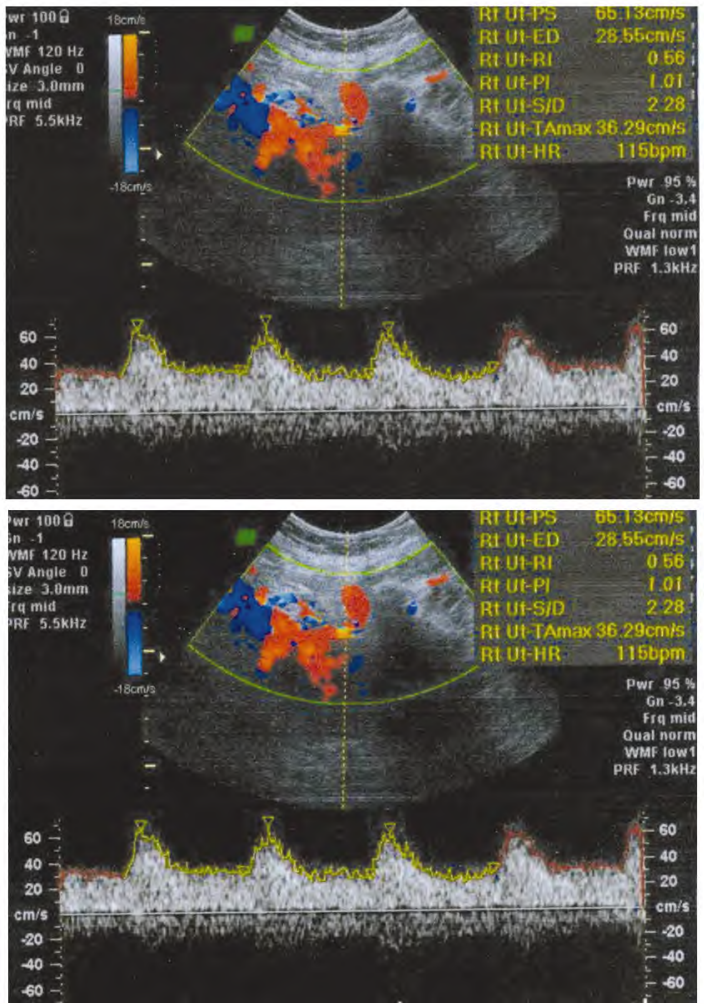

Fig. (6): (Aand B): TAUS of Lt andRt uterine artery Doppler in women with history of previous $1 \mathrm{CS}$ at $35 \mathrm{wk}$ of gestation in which RtUt indices (A) were RI $=0.70$ and $\mathrm{PI}=1.49$, Lt Ut indices $(\mathrm{B})$ were $\mathrm{RI}=0.62$ and $\mathrm{PI}=1.10$, when CS was done, the placenta was normal.

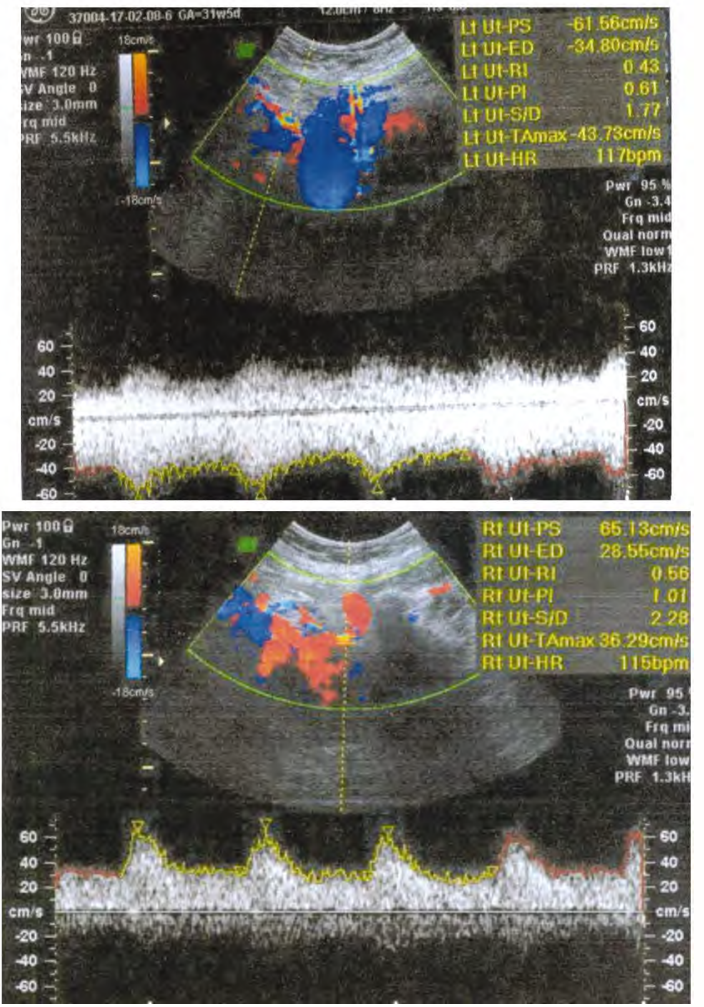

Fig. (7): (Aand B): TAUS of Lt andRt uterine artery Doppler in women with history of previous $4 \mathrm{CS}$ at $33 \mathrm{wk}$ of gestation in which RtUt indices (A) were RI $=0.56$ and PI $=1.01$, Lt Ut indices $(\mathrm{B})$ were $\mathrm{RI}=0.43$ and $\mathrm{PI}=0.61$, when CS was done, the placenta accrete was found 
Statistical analysis: The collected data were statistically analyzed using SPSS 22.0 (SPSS Inc., Chicago, IL, USA) .Quantitive data were expressed as mean \pm standard deviation (SD). Qualitative data were expressed as frequency and percentage. The sensitivity, specificity, positive predictive value (PPV), negative predictive value (NPV) were calculated for color Doppler and 2D sonography.

\section{Results}

The study was included sixty patient with placenta previa detected by ultrasonography with or without accreta either low lying placenta anterior, minor, major and all with history or previous ceserean section. All were examined by color Doppler ultrasound of the uterine arteries to help in antenatal diagnosis of placenta accereta.

Table (1) displayed that all of the studied women are in the middle age group between $20-39$ years old with the mean age of $30.63 \pm 5.07$ years and median was 30.5 years with fifteen. Their gravidity ranged between 2-11. Also their parity ranged between 1-5. Regarding gestional age, it was ranged between $28-36$ weeks with the mean was $34.8 \pm 2.56$ weeks.

Table (1): Demographic data of the studied group.

\begin{tabular}{lll}
\hline Characterstics & Mean \pm SD & Range \\
\hline Mean of age (ys) & $30.63 \pm 5.07$ & $20-39$ \\
Mean of GA at diagnosis of & $34.8 \pm 2.56$ & $28-36$ \\
placenta accrete & $10.83 \pm 0.87$ & $8.4-13.4$ \\
Preoperative Hb (g/dl) & & \\
Gravidity: & \multicolumn{2}{c}{$33(55 \%)$} \\
G2-G4 & $27(45 \%)$ \\
$>$ G5 & \\
No of previous CS: & $20(33.3 \%)$ \\
$p_{1}$ & $17(28.3 \%)$ \\
$p_{2}$ & $15(25 \%)$ \\
$p_{3}$ & $4(6.7 \%)$ & \\
$p_{4}$ & $4(6.7 \%)$ & \\
$p_{5}$ & $46(6.7 \%)$ & \\
History of APH & $34.50 \pm 2.56$ & $28-36$ \\
Gestional age at diagnosis of & \\
placenta accrete by U/S(wks) & \\
\hline
\end{tabular}

Table (2) displayed that 25 patients were met the diagnostic criteria of Placenta accreta by ultrasound and this make the incidence of placenta accreta between women with placenta previa with history of previous cesarean section was $41.7 \%$.

Table (2): Incidence of placenta accrete in the studied group.

\begin{tabular}{lcc}
\hline & \multicolumn{2}{c}{ All women placenta previa } \\
\cline { 2 - 3 } & No. & $\%$ \\
\hline With accrete & 25 & 41.7 \\
Without accrete & 35 & 58.3 \\
\hline
\end{tabular}

Table (3) displayed that no significant difference in the number of gravidity between women with and without placenta accreta with $p$-value 0.356 (NS). Also the number of previous section dose not significantly affect the incidence of placenta accrete with $p$-value : 0.058 (NS).

Table (3): Comparison between the studied groups according to gravidity and previous CS.

\begin{tabular}{|c|c|c|c|c|c|c|}
\hline & \multicolumn{4}{|c|}{ Placenta accrete } & \multirow{3}{*}{$t$-test } & \multirow{3}{*}{$p$-value } \\
\hline & \multicolumn{2}{|c|}{$\begin{array}{l}\text { Absent } \\
(\mathrm{N}=35)\end{array}$} & \multicolumn{2}{|c|}{$\begin{array}{l}\text { Present } \\
(\mathrm{N}=25)\end{array}$} & & \\
\hline & No. & $\%$ & No. & $\%$ & & \\
\hline \multicolumn{7}{|c|}{ Gravidity: } \\
\hline $2-4$ & 21 & 60 & 12 & 48 & 0.848 & $0.356(\mathrm{NS})$ \\
\hline$\geq 5$ & 14 & 40 & 13 & 52 & & \\
\hline \multicolumn{7}{|c|}{ Previous CS: } \\
\hline 1 & 18 & 42.9 & 5 & 20 & 9124 & $0.058(\mathrm{NS})$ \\
\hline 2 & 11 & 31.4 & 6 & 24 & & \\
\hline 3 & 7 & 20 & 8 & 32 & & \\
\hline 4 & 2 & 5.7 & 2 & 8 & & \\
\hline 5 & 0 & 0 & 4 & 16 & & \\
\hline
\end{tabular}

Table (4) showed that the preoperative $\mathrm{Hb}$ $(\mathrm{gm} / \mathrm{dl})$ was significantly low in patients with placenta previa accreta in comparison to women without accreta ( $p$-value : 0.016).

Table (4): Comparison between women with and without placenta accreta as regard preoperative hemoglobin level $(\mathrm{g} / \mathrm{dl})$.

\begin{tabular}{|c|c|c|c|c|}
\hline \multirow{2}{*}{$\begin{array}{l}\text { PreopHb } \\
\text { (g/dl) }\end{array}$} & \multicolumn{2}{|c|}{ Placenta accrete } & \multirow[b]{2}{*}{ Test* } & \multirow[b]{2}{*}{$p$-value } \\
\hline & $\begin{array}{l}\text { Absent } \\
(\mathrm{N}=35)\end{array}$ & $\begin{array}{l}\text { Present } \\
(\mathrm{N}=25)\end{array}$ & & \\
\hline $\begin{array}{l}\text { Mean } \pm \text { SD } \\
\text { Median } \\
\text { (Range) }\end{array}$ & $\begin{array}{l}11.05 \pm 0.74 \\
10.90 \\
(9.90-13.40)\end{array}$ & $\begin{array}{l}10.51 \pm 0.94 \\
10.50 \\
(8.40-12.90)\end{array}$ & 2.476 & $0.016(\mathrm{~S})$ \\
\hline
\end{tabular}

The mean PI of the uterine artery was significantly lower in group of placenta accreta in comparison to patient with previa but, with no statistical significant difference. The mean RI of the uterine artery was significantly lower in the placenta accreta in comparison to placenta previa without accreta. When mean RI of the uterine artery is lesser than 0.59 the risk of having placenta previa with accrete is increased.

Table (5) displayed That the mean RI detected by the uterine artery Doppler velocimetry was significantly low in placenta previa with accreta. As it was $0.656 \pm 0.190$ without accreta and $0.557 \pm$ 0.127 for placenta accreta (Mann Whitney U test; $p$-value $<0.001)$ for the mean uterine artery RI, An increase in this value is associated with a lower risk of placenta accreta. 
Table (5): Comparison between women with and without placenta accreta as regard uterine artery Doppler measurements.

\begin{tabular}{|c|c|c|c|c|c|}
\hline \multirow[b]{2}{*}{$\begin{array}{l}\text { Uterine Doppler } \\
\text { measurements }\end{array}$} & \multirow[b]{2}{*}{$\begin{array}{l}\text { All pregnant women } \\
\qquad(\mathrm{N}=60)\end{array}$} & \multicolumn{2}{|c|}{ Placenta accrete } & \multirow[b]{2}{*}{ Test } & \multirow[b]{2}{*}{$p$-value } \\
\hline & & $\begin{array}{l}\text { Absent } \\
(\mathrm{N}=35)\end{array}$ & $\begin{array}{l}\text { Present } \\
(\mathrm{N}=25)\end{array}$ & & \\
\hline \multicolumn{6}{|l|}{ Mean RI: } \\
\hline Mean \pm SD & $0.615 \pm 0.173$ & $0.656 \pm 0.190$ & $0.557 \pm 0.127$ & $2.253^{*}$ & $0.028(\mathrm{~S})$ \\
\hline Median (Range) & $0.597(0.320-1.050)$ & $0.620(0.320-1.050)$ & $0.550(0.370-0.835)$ & & \\
\hline \multicolumn{6}{|l|}{ Mean PI: } \\
\hline Mean \pm SD & $1.304 \pm 1.037$ & $1.444 \pm 1.194$ & $1.107 \pm 0.746$ & $-1.784 \bullet$ & $0.074(\mathrm{NS})$ \\
\hline Median (Range) & $1.017(0.390-7.235)$ & $1.190(0.390-7.235)$ & $0.900(0.490-2.990)$ & & \\
\hline
\end{tabular}

- Mann Whitney U test. * Independent samples student's $t$-test. $\quad p<0.05$ is significant.

The mean PI determined by uterine artery Doppler velociometry was low in placenta previa with accreta $(1.107 \pm 0.746)$ when compared with mean
PI for placenta previa without accreta but, with no statistical significance difference where Mann Whitney test is equal to -1.784 and $p$-value is $>0.005$.

Table (6): Mean of uterine artery Doppler (RI) for diagnosis of placenta accreta; ROC curve Analysis.

\begin{tabular}{lllllll}
\hline UTA & SN\% & SP\% & PPV\% & NPV\% & Accuracy & AUROC \\
\hline Cut off values & $95 \% \mathrm{Cl}$ & $95 \% \mathrm{Cl}$ & $95 \% \mathrm{Cl}$ & $95 \% \mathrm{Cl}$ & $95 \% \mathrm{Cl}$ & $95 \% \mathrm{Cl}$ \\
Mean RI & $60 \%$ & $71.4 \%$ & $60 \%$ & $71.4 \%$ & $66.6 \%$ & $0.659 *$ \\
$<0.56$ & $(38.7-78.9)$ & $(53.7-85.4)$ & $(38.7-78.9)$ & $(53.7-82.4)$ & $(47.4-82.7)$ & $(0.526-0.777)$ \\
\hline
\end{tabular}

${ }^{*} p$-value $(\mathrm{sig})=0.023(\mathrm{~s})$.

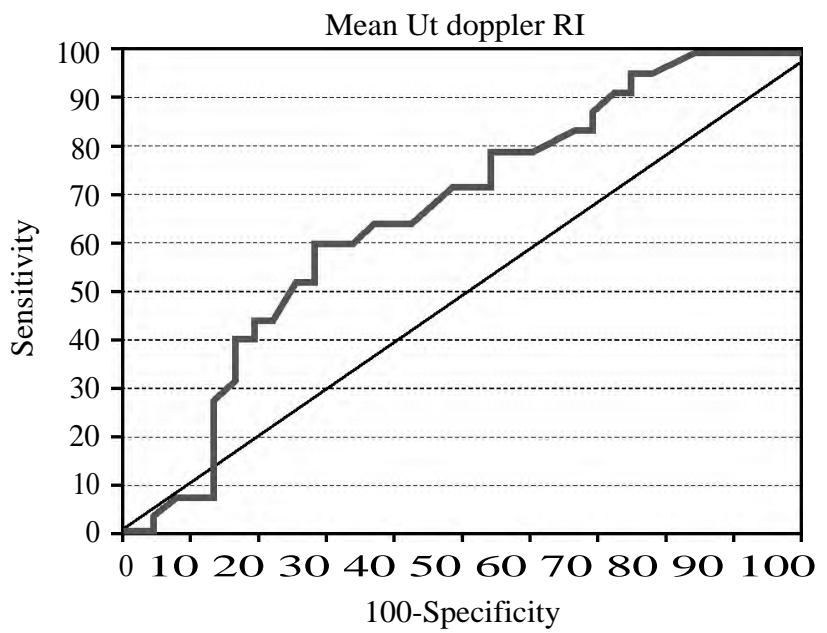

Roc Curve (1): Receiver Operating Charactristic curve; SN: Sensitivity; SP: Specificity; PPV: Positive Predictive Value; NPV: Negative Ppredictive Value; AUROC: Area Under Receiver Operating Charactristic Curve: 95\%CI: 95\%. Con dence interval: $p$-value $<0.05$ is significant.

Fig. (8): Receiver Operating characteristic (ROC) curve of Mean Ut Doppler RI for diagnosis of placenta accreta.

Table (7): Mean of uterine artery Doppler (PI) for diagnosis of placenta accreta; ROC curve Analysis.

\begin{tabular}{lllllll}
\hline UTA & SN\% & SP\% & PPV\% & NPV\% & Accuracy & AUROC \\
\hline Cut off values & $95 \% \mathrm{Cl}$ & $95 \% \mathrm{Cl}$ & $95 \% \mathrm{Cl}$ & $95 \% \mathrm{Cl}$ & $95 \% \mathrm{Cl}$ & $95 \% \mathrm{Cl}$ \\
Mean RI & $64 \%$ & $74.3 \%$ & $64 \%$ & $74.3 \%$ & $70 \%$ & $0.636^{*}$ \\
$<0.93$ & $(42.5-82)$ & $(56.7-87.5)$ & $(42-82.4)$ & $(56.7-87.5)$ & $(50.8-85.2)$ & $(0.502-0.756)$ \\
\hline
\end{tabular}

${ }^{*} p$-value $(\mathrm{sig})=0.057(\mathrm{NSs})$. 


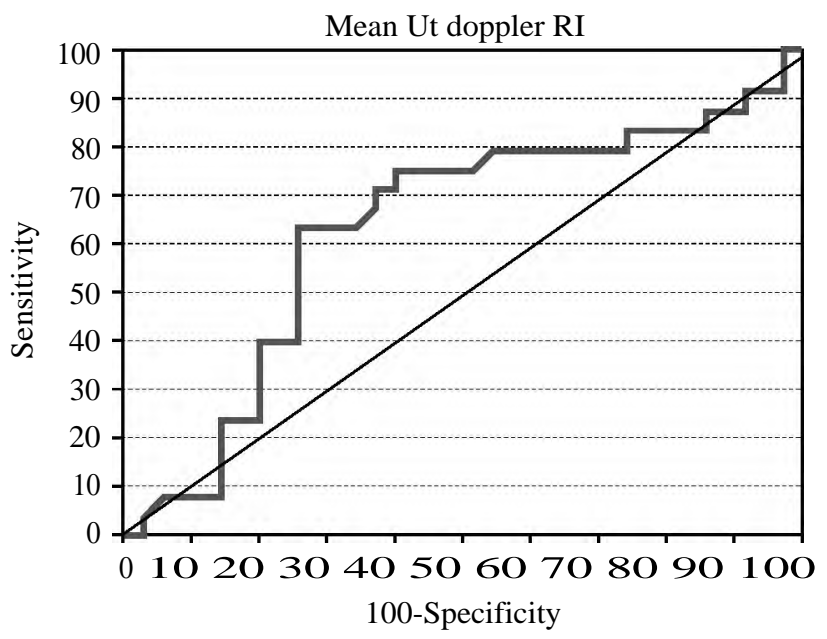

\section{Discussion}

Placenta accreta is considered as a major pregnancy complication that may be associated with massive and potentially life-threatening intrapartum and postpartum hemorrhage [21]. Placenta accreta is associated with with increased incidence of uretral injury, cystectomy, pulmonary embolism and also the reason for emergency postpartum hysterectomy [22].

Early detection of placenta accreta is essential in reducing the morbidities, i.e. bleeding and need for blood transfusion [23]. The gold standard diagnosis of placenta accreta will be determined by histology evaluation [24]

This study was a prospective study to evaluate the value of color Doppler study of the uterine artery in detection of placenta previa accreta in women with previous CS, it included sixty pregnant women diagnosed by ultrasound as placenta previa with or without accreta either low lying placenta anterior, minor, major or centralis and all the cases with history of previous cesarean section. All women were examined by color Doppler ultrasonography of uterine arteries to help in antenatal diagnosis of placenta accreta.Placenta accrete was found in $41.7 \%$ of the studied women.

As regard the number of previous CS this study found that no significant statistical differences between patient with confirmed placenta accrete versus those without accrete $(p$-value $=0.05)$.

This study showed significant reduction in preoperative $\mathrm{Hb}$ concentration $(\mathrm{g} / \mathrm{dl})$ in patients with placenta previa accrete in comparison to those without accreta as to $(10.51 \pm 0.94)$ versus $(11.05 \pm$ $0.74)$ with $p$-value (0.016).
Roc Curve (2): Receiver Operating Charactristic curve; SN: Sensitivity; SP: Specificity; PPV: Positive Predictive Value; NPV: Negative Ppredictive Value; AUROC: Area Under Receiver Operating Charactristic Curve: 95\%CI: 95\%. Con dence interval: $p$-value $<0.05$ is significant.

Fig. (9): Receiver Operating characteristic (ROC) curve of Mean Ut Doppler PI for diagnosis of placenta accreta.

In this study high statistically significant difference was found between women with and without placenta accrete in suspicion of placenta accreta as there were 23 cases were truly positive for suspicion of placenta accreta and two cases were false negative for placenta accreta. There were 34 cases were truly negative for placenta accreta and only one case were false negative for placenta accreta.

Many authors have tried to diagnose of placetna accreta by sonographically done during the routine antenatal care, Hung et al. [26], Comstock et al. [12], Yang et al. [27] Sumigama et al. [28] and Elsayes et al. [29] all reported that conventional 2D gray-scale ultrasonographic criteria for the diagnosis of abnormally adherent placenta can be useful in determining the patient's clinical outcome and for preparing them for surgery.

This study reported that the mean RI determined by uterine artery Doppler velocimetry was significantly low in placenta previa with accreta. As it was $0.656 \pm 0.190$ for placenta without accreta and $0.557 \pm 0.127$ for placenta accrete $(p<0.001)$.

This result was in agreement with the study done by Cho et al. [30] to evaluate the efficacy of uterine artery Doppler velocimetry in diagnosing placenta previa accreta and they found that uterine artery Doppler mean RI lesser than 0.40 (OR 3.39; $95 \%$ CI 1.41, 8.16) was associated with increased risk of having placenta previa with accrete.

They also found significant reduction in the mean PI of the uterine artery in patients with placenta accrete in patients with placenta accrete as compared to those without accrete ( 0.51 versus $0.57 ; p=0.002$ ). 
The current study reported that the mean PI obtained from uterine artery Doppler in women with placenta accreta was not statistically significant lower than that in placenta previa without accreta as it was $1.107 \pm 0.746$ versus $1.444 \pm 1.194$ $(p$-value $=0.074)$.

The cut off value of mean uterine artery Doppler PI for placenta accrete obtained from ROCK curve was $\leq 0.93$, AUROC (0.636), SN (64\%), SP (74.3\%), PPV (64\%), NPV (74.3\%), accuracy $(70 \%)$ and $\mathrm{CI}(95 \%)$.

This result was in agreement with the study of Cho et al. [30] for evaluation of the potential value of colr Doppler study of the in diagnosing placenta accrete and they found that the mean PI of the uterine artery was significantly lower in the placenta accreta group compared to previa alone $(0.51$ versus $0.57 ; p=0.002)$, with an increase in the mean PI by 0.01 , the odds ratio for placenta accrete decreased by $0.94(p<0.001)$.

This study reported that the uterine artery Doppler RI is reduced in placenta previa with accreta patients in comparison to placenta previa without accreta or normal pregnancy. The mean RI of the uterine artery lesser than 0.40 there is associated with 3.39-fold increased risk of having placenta previa with accreta (OR 3.39; 95\% CI 1.41, 8.16).

The study done by Kwak et al. [32] showed that uterine artery Doppler RI is reduced in PPA compared with PP. When the mean RI of the uterine artery becaming lesser than 0.40 , patients who have placenta previa were at increased risk of having placenta accrete (oods ratio (OR) 3.39; $95 \%$ confidence interval (CI) 1.41, 8.16), low uterine artery Doppler RI is independent risk factor of placenta accreta in placenta previa patients.

In the current study, we reported that the incidence of placenta accreta in patients with previous cesarean section and currently presented with anterior low implantation placenta (low lie, previa minor, previa major or complete centralis) was $41.7 \%$, (25 cases) from 60 cases whom included in the study and between them 20 cases were with $\geq 2$ previous section.

\section{Conclusion:}

Ultrasonography is the first modality of choice most sensitive and commonly used imaging modality for the detection of placenta accreta because it is accurate, non-invasive, inexpensive, and timesaving technique. Combined 2D ultrasonography with Color Doppler Ultrasound increasing its accuracy in diagnosis of accreta.
Color Doppler study of the uterine artery can be a useful tool for predicting placenta accreta. However, the uterine artery Doppler value alone may be inconclusive for differentiating placenta accreta from placenta previa without accreta. Therefore combination of uterine artery Doppler with other ultrasound predicting signs will improve the diagnostic accuracy of placetna accreta.

\section{References}

1- USTA I.M., HOBEIKA E.M., MUSA A.A., GABRIEL G.E. and NASSAR A.H.: Placenta pervia-accreta: Risk factors and complications. Am. J. Obstet. Gynecol., 193: 1045-9, 2005.

2- DWYER B.K., BELOGOLOVKIN V., TRAN L., RAO A., CARROLL I., BARTH R. and CHITKARA U.: Prenatal diagnosis of placenta accreta: sonography or magnetic resonance imaging?. Journal of Ultrasound in Medicine, 27 (9): 1275-81, 2008.

3- JAUNIAUX E., COLLINS S. and BURTON G.J.: Placenta accreta spectrum: Pathophysiology and evidence-based anatomy for prenatal ultrasound imaging. Am. J. Obstet. Gynecol., 218: 75-87, 2018.

4- FITZPATRICK K.E., SELLERS S., SPARK P., KURINCZUK J.J., BROCKLEHURST P., et al.: Incidence and risk factors for placenta accreta/increta/percreta in the UK: A national case-control study.; PLOS ONE 7: e52893. doi: 10.1371/journal.pone.0052893, 2012.

5- Royal College of Obstetric and Gynaecologist: Placenta previa, Placenta Previa Accreta and Vasa Previa : Diagnosis and Management. London, England: Royal College of Obstetricians and Gynaecologists, 26.Green-top guidelines 27, 2011.

6- BOWMAN Z.S., ELLER A.G., BARDSLEY T.R., GREENE T., VERNER M.W. and SILVER R.M.: Risk factors for placent accreta: A large prospective cohort.Am. J. Perinatal, 31: 799-804, 2014.

7- JAUNIAU X.E., COLLINS S. and BURTON G.J.: Placenta accrete spectrum: Pathophysiology and evidencebasedanatomy for prenatal ultrasound imaging. Am. J. Obstet. Gynecol., 218: 75-87, 2018

8- BELFORT M.A.: Placenta accreta. Am. J. Obstet. Gynecol., Vol. 203: pp. 430-439, 2010.

9- MOGOS M.F., SALEMI J.L., ASHLEY M., WHITEMAN V.E. and SALIHU H.M.: Recent trends in placenta accreta in the United States and its impact on maternal-fetal morbidity and healthcare-associated costs, 1998-2011. J. Matern Fetal Neonatal Med., 29: 1077-82, 2016.

10- JANG D.G., LEE G.S.R., YOON J.H. and LEE SG.: Placenta percreta-induced uterine rupture diagnosed by laparoscopy in the first trimester: case report. Int. J. Med. Sci., Vol. 8: pp. 424-427, 2011.

11- SHAMSHIRSAZ A.A., FOX K.A., SALMANIAN B., DIAZ-ARRASTIA C.R., LEE W., BAKER B.W., et al.: Maternal morbidity in patients with morbidly adherent placenta treated with and without a standardized multidisciplinary approach. Am. J. Obstet. Gynecol., 212: 218.e1-912, 2015. 
12- COMSTOCK C.H.: Antenatal diagnosis of placenta accreta: A review. Ultrasound Obstet. Gynecol., Vol. 26 pp. 89-96, 2005.

13-ALKAZALEH F., GEARY M., KINGDOM J., KACHURA J.R. and WINDRIM R.: "Elective non-removal of the placenta and prophylactic uterine artery embolization postpartum as a diagnostic imaging approach for the management of placenta percreta: A case report, " Journal of Obstetrics and Gynecology Canada, Vol. 26, No. 8, pp. 743-746, 2004.

14- WONG H.S., YING K.C., ZUCCOLLO J., TAIT J. and PRINGLE K.C.: "Evaluation of sonographic diagnostic criteria for placenta accreta", Journal of Clinical Ultrasound, Vol. 36, No. 9, pp. 551-559, 2008.

15- SHIH J.C., JARAQUEMADA J.M.P., SU Y.N., et al.: placentas "Role of three-dimensional power Doppler in the antenatal diagnosis of placenta accreta: Comparison with gray-scale and color Doppler techniques", Ultrasound in Obstetrics and Gynecology, Vol. 33, No. 2, pp. 193 203, 2009.

16- MASSELLI G., BRUNELLI R., CASCIANI E., et al.: Magnetic resonance imaging in the evaluation of placental adhesive disorders: Correlation with color Doppler ultrasound. Eur. Radiol., Vol. 18 No. (6): pp. 1292-1299, 2008.

17- HOFFMAN-TRETIN J.C., KOENIGSBERG M., RABIN A. and ANYAEGBUNAM A.: Placenta accreta. Additional sonographic observations. J. Ultrasound Med., Vol. 11 No. (1): pp. 29-34 21, 1992.

18-BAUGHMAN W.C., CORTEVILLE J.E. and SHAH R.R.: Placenta accreta: Spectrum of US and MR imaging findings. Radiographics, Vol. 28 No. (7): pp. 1905-1916, 2008.

19- HUDON L., BELFORT M.A. and BROOME D.R.: Diagnosis and management of placenta percreta: A review. Obstet. Gynecol. Surv., Vol. 53 No. (8): pp. 509-517, 1998.

20- BAHARTI GAHTORI: Doppler in pregnancy, Abnormal uterine artery Doppler (slid share) slide 20, 2014.

21- SILVER R.M., LANDON M.B., ROUSE D.J., LEVENO K.J., SPONG C.Y., THIM E.A., et al.: Maternal morbidity associated with multiple repeated ceserean deliveries. Obs. Gynecol., 107: 1226-32, 2016.

22- FARANESH R., SHABTAI R., ELIEZER S. and RAED S.: Suggested approach for management of placenta percreta invading the urinary bladder. Obstetrics and Gynecology, 110 (2): 512-5, 2007.
23- SATIJA B., KUMAR S., WADHWA L., GUPTA T., KOHLI S., CHANDOKE R. and GUPTA P.: Utility of ultrasound and magnetic resonance imaging in prenatal diagnosis of placenta accreta: A prospective study. The Indian Journal of Radiology and Imaging, 25 (4): 464, 2015.

24- TIKKANEN M., PAAVONEN J., LOUKOVAARA M. and STEFANOVIC V.: Antenatal diagnosis of placenta accreta leads to reduced blood loss. Acta. ObstetriciaetGynecologica Scand Inavica, 90 (10): 1140-6, 2011.

25- DANNHEIM K., SHAINKER S.A. and HECHT J.L.: Hysterectomy for placenta accreta; methods for gross and microscopic pathology examination. Archives of Gynecology and Obstetrics, 293 (5): 951-8, 2016.

26- HUNG T.H., SHAU W.Y., HSIEH C.C., CHIU T.H. and HSU J.J.: Risk factors for placenta accreta. Obstetrics and Gynecology, 93 (4): 545-50, 1999.

27- YANG J.I., LIM Y.K., KIM H.S., CHANG K.H., et al.: sonographic findings of placental lacunae and the predction of adherent placenta in women with placenta previatotalis and prior cesreansection. Ultrasound Obstet. Gynecol., 28: 178-82, 2016.

28- SUMIGAMA S., ITAKURA A., OTA T., OKADA M., KOTANI T., HAYAKAWA H., YOSHIDA K., ISHIKAWA K., HAYASHI K., KURAUCHI O. and YAMADA S.: Placenta previa increta/percreta in Japan: a retrospective study of ultrasound findings, management and clinical course. Journal of Obstetrics and Gynaecology Research, 33 (5): 606-11, 2007.

29- ELSAYES K.M., TROUT A.T., FRIEDKIN A.M., LIU P.S., BUDE R.O., PLATT J.F. and MENIAS C.O.: Imaging of the placenta: A multimodality pictorial review. Radiographics, 29 (5): 1371-91, 2009.

30- CHO H., HWANG H., KWON J., PARK Y. and KIM Y.: Usefulness of uterine artery Doppler velocimetry in diagnosing placenta accreta in placenta previa patients. Ultrasound in Obstetrics and Gynecology, 42 (s1): 41, 2013.

31- FINBERG H.J., WILLIAMS J.W.: Placenta accreta: prospective sonographic diagnosis in patients with placenta previa and prior cesarean section. Journal of Ultrasound in Medicine, 11 (7): 333-43, 1992.

32- KWAK D.W., KWON J.Y., KIM Y.H. and PARK Y.W.: Is it possible to predict placenta accreta by uterine artery Doppler velocimetry in placenta previa. Ultrasound in Obstetrics and Gynecology, 32 (3): 421, 2008. 


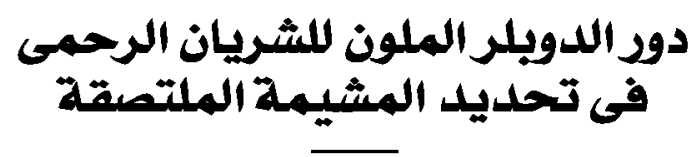

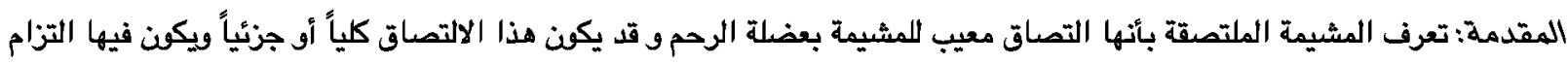

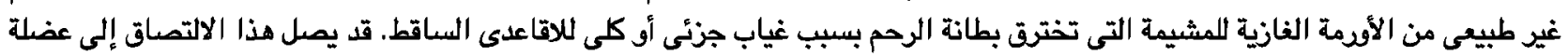

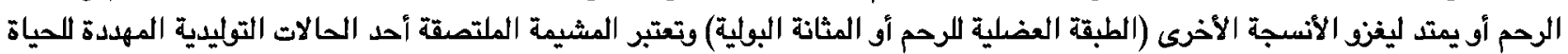

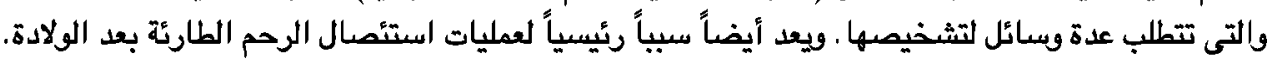

الهدف من البحث: تقييم أهمية الدوبلر الملون اللشريان الرحمى فى تشخيص المشيمة الملتصقة لدى السيدات الحوامل اللاتى سبق لهن ولادة قيصرية

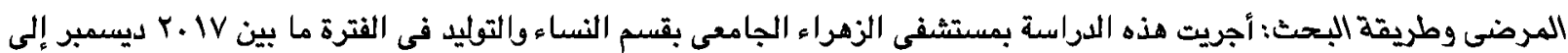

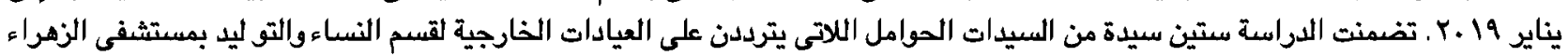

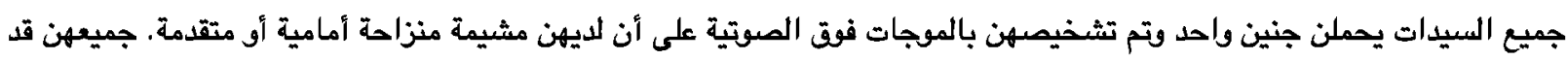

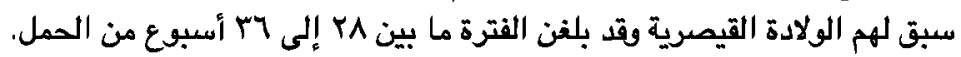
النتائج:وصلت نسبة المشيمة الملتصقة VI\&\& من السيدات التى أجريت عليهن الدراسة.

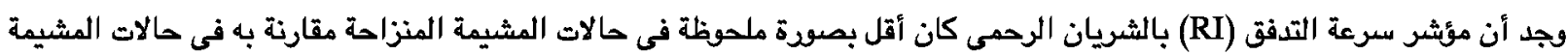

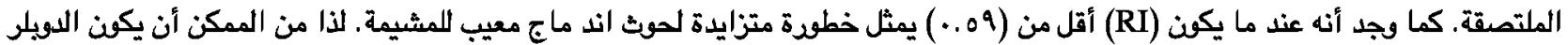

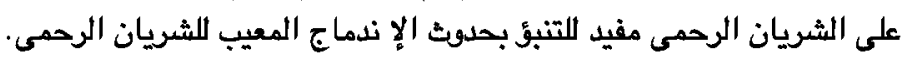
الخلاصة: توصى الدراسة بأهمية فحص المريضة بكل من الموجات فوق الصوتية والدوبلر اللشريان الرحمى اللتشخيص عيوب المشيمة

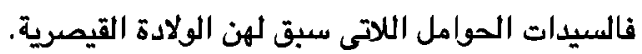

